\title{
MARXISMO: CONTRIBUIÇÃO DAS MULHERES
}

\section{MARXISM: THE CONTRIBUTION OF WOMEN}

\section{EL MARXISMO: EL APORTE DE LAS MUJERES.}

DOI: http://dx.doi.org/10.9771/gmed.v12i1.38255

Maria de Fátima Rodrigues Pereira ${ }^{1}$

Esta edição é dedicada às contribuições das mulheres ao marxismo, seja porque em suas vidas participaram de movimentos revolucionários, seja em virtude de que fizeram avançar as reflexões, proposições, teses da teoria social, política, educacional fundada por Marx e Engels no século XIX e ainda em construção porque histórica e colada à vida prática de homens e mulheres. Trata-se, afinal de dar relevância a mulheres que de alguma maneira realizaram e realizam em suas vidas atividades revolucionárias e fazem suas lutas por um mundo socialista.

Nas lutas das classes trabalhadoras, travadas desde o final do século XIX até hoje, não faltaram mulheres que estiveram na linha de frente, escrevendo, panfletando, organizando partidos políticos, fazendo escolas, escrevendo teses, fazendo avançar a teoria social marxista em suas esferas. Porém, não tem sido muito lembradas e nem estudadas, a exceção de poucas como Rosa Luxemburgo, Clara Ztkin, Nadejda Krupyskaia, Elexandra Kollontai, Eleanor Marx. Só por si, essa situação denota as dificuldades tanto para o campo socialista como para a presença das mulheres no marxismo.

Há uma linha de estudos que toma as contribuições das mulheres, independente das contradições e lutas entre capital e trabalho, prende-se ao eixo da conquista de direitos, da igualdade de gêneros.

Os destaques que se fazem e por isso a eleição dos textos publicados levam em conta o imbricamento entre as lutas anti-capital e as ações das mulheres marxistas.

Engels na sua obra a Origem da Família da Propriedade Privada e do Estado esclarece como historicamente foram alteradas as relações domésticas entre homens e mulheres na passagem do comunismo primitivo ao regime de propriedade privada e a correspondente divisão social do trabalho.

Diz ele:

A divisão do trabalho na família havia sido a base, para a distribuição da propriedade entre o homem e a mulher. Essa divisão do trabalho na família 
continuava sendo a mesma, mas agora transtornava as relações domésticas, pelo simples fato de ter mudado a divisão do trabalho fora da família. A mesma causa que havia assegurado à mulher sua anterior supremacia na casa - a exclusividade no trato dos problemas domésticos - assegurava agora a preponderância do homem no lar: o trabalho doméstico da mulher perdia agora sua importância, comparado com o trabalho produtivo do homem; este trabalho passou a ser tudo; aquele, uma insignificante contribuição. Isso demonstra que a emancipação da mulher e sua equiparação ao homem são e continuarão sendo impossíveis, enquanto ela permanecer excluída do trabalho produtivo social e confinada ao trabalho doméstico, que é um trabalho privado. A emancipação da mulher só se torna possível quando ela pode participar em larga escala, em escala social, da produção, e quando o trabalho doméstico lhe toma apenas um tempo insignificante. Esta condição só pode ser alcançada com a grande indústria moderna, que não apenas permite o trabalho da mulher em grande escala, mas até o exige, e tende a cada vez mais a transformar o trabalho doméstico privado em uma indústria pública.

A supremacia efetiva do homem na casa tinha posto por terra os últimos obstáculos que se opunham ao seu poder absoluto. Esse poder absoluto foi consolidado e eternizado pela queda do direito materno, pela introdução do direito paterno e a passagem do matrimônio sindiásmico à monogamia (ENGELS).

Desde então, a posse da propriedade privada, sua concentração nas mãos de poucos e a consequente desapropriação de muitos, tem levado a situações sociais extremas de não reconhecimento das classes trabalhadoras, despossuídas de propriedade, entre as quais as mulheres. Neste sentido, as contribuições das mulheres compõem as lutas da classe produtora de valor, fazemse no interior da emancipação da classe, com suas singularidades reais que exigem a superação concreta da exploração do trabalho feminino, do seu corpo, do seu tempo.

Nesta edição organizam-se as contribuições das mulheres ao marxismo trazendo a lume seis tipos/temas de textos. O primeiro compõe a sessão debates, espelha os movimentos revolucionários das mulheres. O segundo é apresentado em textos sobre condições de trabalho de mulheres. O terceiro comparece em estudos teóricos de aprofundamento da teoria marxista e ocupa lugar no meio da sessão debates. O quarto é composto por artigos nos quais seus autores orientados pela teoria social e de conhecimento marxista desvelam a realidade objetiva da vida em suas várias manifestações. O quinto está na sessão entrevista na qual há um debruçamento sobre vários temas relacionados ao marxismo. O sexto constitui-se com o texto clássico e as resenhas que apresentam ao leitor, produções de marxistas. De todo o modo objetiva-se dar a conhecer, debater e apropriar as contribuições das marxistas às classes trabalhadoras e, assim, avançar de maneira a se realizarem as necessárias reflexões sobre os limites do atual modo de existência e sua superação.

As referidas contribuições estão presentes nos artigos que se trazem a lume e que generosamente seus autores entregaram à Germinal para que sejam submetidos ao conhecimento, ao debate e à crítica e, ainda que tenham sido organizados em tipos/temas, todos convergem uns com os outros.

Os movimentos revolucionários de mulheres marxistas comparecem na sessão debates composta por três artigos, são painéis onde são apresentadas aos leitores as mulheres em suas lutas. Maria Lygia Quartim de Moraes em Raízes do feminismo político e embates atuais traça um quadro histórico 
das lutas das mulheres, desde o século XVIII até aos dias atuais, contextualiza-as, aponta a presença nas Internacionais Socialistas, apresenta Clara Zetkin e Alexandra Kollontai como representantes do socialismo revolucionário, Simone de Beauvoir como uma "das intelectuais que mais contribuíram para as profundas transformações na condição da mulher que marcaram" o século XX, circunstancia o feminismo brasileiro entre 1975 e 1985, vai compondo um perfil dos movimentos feministas no Brasil e os desafios que se colocam, um deles o "problema político dos identitarismos [que] reside em ignorar a dimensão de classe". No mesmo sentido de pintar um quadro geral e confluindo para ilação semelhante, coloca-se o artigo intitulado O papel das organizações de mulheres e partidos na Rússia pré-revolucionária, suas autoras Nataly Batista de Jesus e Silvana Calvo Tuleski apresentam um mapeamento dos movimentos feministas na Rússia pré revolucionária, apontam a luta por igualdade de direitos como pauta em comum e as divergências quanto à origem das condições das mulheres e às finalidades das suas lutas. As autoras sinalizam que "por mais substancial que sejam os direitos conquistados pelas mulheres numa sociedade de classes, estes se tornam insuficientes para sua emancipação e consequentemente para a humanidade", há que lutar pelo fim da sociedade de classes. Completa esta sessão o texto de Marcia Santos Leme intitulado Entre a dor e as "vožes do silêncio": a organização social das mulheres e o feminismo socialista, de maneira poética, narra-nos com delicada e firme costura com a formação social a tragédia das mulheres trabalhadoras brasileiras, simbolizadas em Mirtes, mãe do menino Miguel. Traça desafios para uma "nova sociabilidade, onde a dor de Mirtes transforme 'as vozes do silêncio', [incluído a atuação nos sindicatos, com destaque para o Andes], em reação organizada para emancipação da humanidade”.

A Sessão artigos traz um rico painel de 28 produtos, procurou-se agrupa-los por temas assemelhados e ou afins e de acordo com os tipos de textos já explicitado anteriormente. Os 11 primeiros dizem respeito às condições de trabalho, de educação e contribuições de destacadas marxistas. Ana Elisa Cruz Corrêa e Ana Carolina Maria de Andrade no texto intitulado Qual o papel do trabalho doméstico feminino no modo de produção capitalista? uma análise comparativa das interpretações de Silvia Federici e Roswitha Scholz, abordam o trabalho doméstico feminino, consideram e comparam os estudos da filósofa ítalo-estadunidense Silvia Federici e Roswitha Scholz, "pedagoga e filósofa alemã integrante do grupo KRISIS e de sua posterior cisão, o grupo EXIT", contribuem para o esclarecimento da "realidade capitalista patriarcal". Mariana Silveira Santos Rosa em seu artigo Educação das mulheres na bistória do Brasil: a contribuição de Heleieth Saffioti, apresenta com base nos estudos sociológicos de Saffioti a educação formal de meninas e mulheres no período colonial brasileiro, destaca as limitações que estão postas à educação das mulheres em formações sociais capitalistas. Ainda, sobre as contribuições de Saffiotti é o texto de Marco Antonio de Oliveira Gomes, Ana Paula Aires Rodrigues, Crislaine Aparecida Pita e Daniela Azarias Ferreira da Silva- Heleieth Saffioti e a educação: contribuições para o debate, objetivam trazer ao debate o legado teórico e o pioneirismo da obra Saffioti e sua relação com a educação. No texto - Política e educação: observações acerca de Inessa Armand feminista, revolucionária e educadora, Anita Helena Schlesener e Gisele Masson, apresentam essa 
revolucionária russa e suas contribuições em diferentes momentos, destacam a atuação de mulheres anônimas para que a Revolução de outubro de 1917 acontecesse. No artigo- $A$ análise de Vânia Bambirra acerca da opressão das mulheres latino-americanas no lastro da teoria marxista da dependência, Sandra Maria Marinho Siqueira, traz ao leitor a militante marxista Vânia Bambirra, destaca sua obra no conjunto de estudos sobre a América Latina e as lutas anti -imperialistas. Deste mesmo painel sobre mulheres revolucionárias e suas contribuições comparece o texto de Sandra Maria Marinho Siqueira e de Victor Bruno Marinho Pereira- Aportes para a compreensão da opressão da mulher no capitalismo, no qual o objetivo é apresentar com contribuições de Friederich Engels, Sérgio Lessa, Eleanor Burke Leacock, Heleieth Saffioti, e Angela Davis a "origem da opressão e apontar elementos específicos da sua manifestação na sociabilidade capitalista". Qelli Viviane Dias Rocha e Ana Paula Silveira em seu texto- As contribuições de Clara Zetkin para as lutas feminista, anticapitalista e antifascista- tecem considerações sobre a opressão das mulheres sob as relações capitalistas de produção e apresentam as contribuições de Clara Zetkin para a emancipação feminina. Em Olga Benário Prestes e a questão democrática, sua autora Anita Leocádia Prestes tece fino nexo entre o legado da sua mãe Olga Benário Prestes e "o tipo de democracia pela qual deveríamos nos mobilizar para assegurá-la a amplos setores populares". Lucas Carvalho Preto apresenta em seu texto- A lógica-categorial da desigualdade nos Manuscritos marxianos de 1844- que a desigualdade do ponto de vista da teoria social marxista tem por fundamento a posse privada dos meios e produção e a exploração da força de trabalho da classe trabalhadora. No artigo- $O$ nanfrágio do Titanic: a vida das mulheres trabalhadoras em momentos de catástrofe, sua autora Ana Karen Oliveira, recorrendo à figura literária da metáfora, estabelece comparações entre a tragédia das mulheres trabalhadoras quando do naufrágio do Titanic e a que vivemos hoje com a crise do modo de produção capitalista agravada pela pandemia da Covid-19. Paula Marcelino e Lidiane Soares Rodrigues comparecem com o texto intitulado As marxistas nas universidades brasileiras. As autoras apresentam pesquisa sobre a presença e atuação de marxistas nas universidades brasileiras, informam que se trata de resultados parciais de investigação sobre o tema anunciado, apresentam procedimentos metodológicos, organização e análises dos dados coletados nos anos de 2013 e 2014. As autoras em texto alongado e detalhado submetem seu estudo à apreciação dos leitores da Germinal.

Os três textos seguintes tem acentuado caráter teórico, a virtude de sua presença reside na possiblidade de poderem interpelar pesquisadores e estudiosos a conhecer e enveredar em investigações rigorosas de temas sempre necessários ao desvelamento das atuais e complexas relações de produção da vida, configuram-se contribuições à teoria marxista. No texto intitulado Gênero e marxismo: contribuiçôes para a história das ciências, Carolina Queiroz Santana, Ingrid Silva de Andrade e Victor Ferreira Dias Santos a partir do questionamento: "Qual a contribuição da teoria marxista e do feminismo marxista para a história das mulheres nas ciências?" apresentam quatro teses: a refutação sobre a superioridade masculina, "por mero essencialismo biológico", que a "análise do feminismo marxista à categoria de gênero proporciona uma crítica a ciência pautada em determinações 
absolutas"; a defesa pelo feminismo marxista do espaço privado como esfera pública; que o marxismo se apresenta importante para a escrita de história das mulheres nas ciências. Leonardo Celin e Márcia Luzia Cardoso Neves em artigo intitulado Ciência, tecnologia e capitalismo monoplolista tecem relações entre estas três categorias presentes na vida prática contemporânea. Elza Margarida de Mendonça Peixoto, em seu texto- Investigações sobre o tema da prática: Contribuições de José Barata-Moura para o debate pré- profissional de professores, mergulha na obra desse filósofo português para esquadrinhar a sua compreensão de prática e apontar aportes à formação de professores.

Mais 14 artigos completam esta sessão, são contribuições ao tema da educação: educação e trabalho, educação e movimentos sociais, educação popular, educação e reestruturação produtiva, gestão escolar, política do Banco Mundial para a juventude, privatização e mercadorização da educação, Base Nacional Comum Curricular. Efetivamente, no vasto, variado e complexo painel que se apresenta em seguida seus autores refletem primordialmente sobre educação em seus vários aspectos. Assim, no texto - Auto-organização da escola do trabalho em Krupskaya e Pistrak: análise inicial sobre a autogestão estudantil a partir da experiência pedagógica soviética, Jaírla Bianca Aires Praciano e Raphael Alves Feitosa apresentam, com base nas obras de Nadejda Krupskaya, Moisy Pistrak e bibliografia complementar, a categoria auto- organização para a escola do trabalho, apontam que "a autodireção é capaz de proporcionar aos estudantes concepções sobre organização, autonomia e coletividade". De Soares dos Santos e Suely Aparecida Martins é o artigo intitulado A relação trabalho e educação na pedagogia socialista russa, explicitam os fundamentos marxistas dessa educação, apontam seu legado e experiências suscitadas. Em Educação, trabalho e movimentos sociais: uma reflexão crítica da educação popular no Brasil, Acacio Figueredo Nascimento e Bianca Sthephanny Martins Gomes estabelecem nexos entre as formas do trabalho, a perda de direitos, as práticas fragmentadas dos movimentos sociais e a necessária superação, para uma concepção crítica da Educação Popular no Brasil. Denis Fernando Barcellos Angelo e Tanise Baptista de Medeiros no texto- Educaşão e reestruturação produtiva: neoliberalismo, pós-modernidade e o "aprender a aprender", retomam um tema sempre necessário, estabelecem nexos entre a base produtiva, ideologias, epistemologias pós -modernas e as pedagogias do aprender a aprender. No artigo intitulado Diálogos com a bistória da educação profissional no Brasil: permanências e contradições, Mad Ana Desirée Ribeiro Castro, Claudia Borges Costa e Sebastião Cláudio Barbosa apresentam permanências históricas da educação profissional no Brasil, "impeditivos" a uma educação emancipatória, por outro lado apontam contradições como possiblidades reais a uma formação "integrada". O tema da Gestão escolar para a Pedagogia Histórico - Crítica comparece no texto de Aline Cristina Santana Rossi e Célia Beatriz Piatt, intitulado - Gestão escolar e conhecimento: a função social da escola a partir da pedagogia histórico-crítica, trata-se de uma contribuição ao desenvolvimento da Pedagogia Histórico Crítica em construção, sinalizando que à gestão escolar cabe atender à finalidade da socialização dos conhecimentos em suas formas mais desenvolvidas. Roberto Antonio Deitos analisam no artigo - A politica da qualidade educacional para o banco mundial proposta no documento: uma agenda de competências e empregos para a jwventude de 2018, a concepção de competência expressa no 
documento Competências e Empregos: Uma Agenda para a Juventude”, de 2018, do Banco Mundial, após apresentarem análise do tema entendem a política proposta pelo Banco Mundial afinada com a formação do capital humano. Zuleide Silveira em Os rumos da educação em questão: da "hegemonia às avessas" à crise de hegemonia, lançando mão do conjunto categorial capitalismo dependente, fascismo dependente, hegemonia às avessas e crise de hegemonia, analisa a continuidade e descontinuidade dos governos liberais desde a década de 1990, para apontar a perda de direitos da classe trabalhadora, privatização e mercadorização da educação. Em A interlocução entre estado e mercado na elaboração da Base Nacional Comum Curricular, Jacqueline Lopes Freire e Mario Borges Netto discorrem sobre o esvaziamento democrático no processo histórico da elaboração da BNCC, evidenciam o caráter de classe de seus proponentes, apoiadores e do Movimento pela Base. Vânia Pereira Moraes Lopes e Antonia Almeida Silva no artigo- Responsabilidade social empresarial e ativismo social na educação pública do município de Feira de Santana, analisam a presença dos empresários na educação escolar e as formas pelas quais se realizam essa "intervenção", na educação pública. O texto - A mulher na brincadeira do boi-bumbá de Parintins: no ritmo da exploração e da opressão de Elizandra Garcia da Silva é dedicado a apresentar o caráter de explorado no trabalho de mulheres na festa do Boi-Bumbá de Parintins. Marlon Messias Santana Cruz e Sebastião Carlos dos Santos Carvalho no texto O empoderamento e a subversão: a cultura corporal e autoafirmação das(os) estudantes negras(os) na escola, retomam a função social da escola para relatarem e defenderem a prática pedagógica com conteúdos da cultura corporal de matriz africana. Gabriel Vielmo Gomes e Maristela da Silva Souza, no texto- A secundarização da educação física na reforma do ensino médio, relacionam a política educacional, afeta aos interesses do capital e a posição de desprestígio da Educação Física/Cultura Corporal com Lei 13.415 e da Base Nacional Comum Curricular. Em Educação física e formação humana omnilateral: limites e possibilidades da abordagem críticosuperadora, Zuleyka da Silva Duarte propõe articulação entre as teorias críticas da educação e as da Educação Física, apresenta a defesa da formação omnilateral e coloca desafios à abordagem teórica Crítico Superadora.

As contribuições na Sessão Entrevista são reflexões da Professora Maria de Fátima Félix Rosar, destacada educadora militante das causas das classes trabalhadoras. Esclarece, entre outros temas, as referências que lhe aproximaram do marxismo, suas posições em relação às políticas educacionais no contexto brasileiro, seu trabalho em importantes universidades públicas brasileiras, a presença de marxistas na história da educação brasileira, desenvolvimento do marxismo e das pesquisadoras marxistas no Grupo de Estudos e Pesquisas História, Sociedade e Educação no Brasil (Histedbr), suas perspectivas para a educação face a políticas que usam fake news como instrumento de poder.

A sessão clássicos traz três textos de Rosa Luxemburg: uma carta escrita na prisão de Breslau - "Breslau, antes de 24. 12. 1917”, endereçada a sua amiga Sonia Liebknecht, esposa de Karl Liebknecht que junto com Rosa tinha fundado a Liga Espartaquista, um grupo à esquerda e dissidente da social democracia alemã. Os espartaquistas colocaram -se como anti-imperialistas, anti-militaristas 
e se posicionaram contra o apoio dos dirigentes da social democracia à Primeira Guerra Mundial, considerando-o um ato de traição. Junto com a carta publicam-se dois ensaios que circularam na imprensa da época em que foram redigidos: A socialização da Sociedade e A Proletária que tratam respectivamente da revolução do proletariado/realização do socialismo e a condição histórica da mulher burguesa e proletária, um manifesto pela luta das mulheres proletárias. Presa várias vezes, Rosa foi fuzilada e seu corpo jogado no rio Landwedrkanal, em Berlim, no ano de 1919. Rosa Luxemburg foi uma revolucionária marxista, antirreformista, defensora da greve de massas, "pioneira do socialismo democrático, em virtude da sua defesa intransigente da autonomia criadora das massas contra o burocratismo paralisante das organizações" (LOUREIRO, p. 88). Na carta que ora se disponibiliza, o leitor pode apreciar a sensibilidade poética de Rosa e conhecer o traço literário dessa revolucionária, já nos dois textos para a imprensa sobressai a revolucionária apontando o caminho a ser seguido pelos proletários. Apresentam-se ainda, duas resenhas: de Angela Davis e a luta por liberdade obra resenhada por Nádia Magalhães Duarte e Império do capital de Hellen Meiksins Wood, resenhada por Elson Moura Dias Júnior.

O conjunto de trabalhos que Germinal traz a lume e que generosamente seus autores oferecem ao debate, traçam as vidas e lutas de mulheres marxistas, apontam os limites e possibilidades dos processos emancipatórios. Os textos ora apresentados sugerem angústias e esperanças. Vem bem em uma época em que a crise estrutural do modo de produção capitalista é sentida dramaticamente, agravada pela pandemia de proporções trágicas para todo o planeta, a Covid- 19, cujo remédio ainda é o isolamento social, mas cujas possibilidades de fazê-lo não está para todos, muito menos para as classes trabalhadoras e nelas as mulheres que, sem propriedade são obrigadas a granjear o pão nosso de cada dia. Que esta edição da Germinal seja desfrutada e inspire à luta pela vida para todos!

\section{Referências}

ENGELS, Friedrich. A Origem da Família da Propriedade Privada e do Estado. In: https://www.marxists.org/portugues/marx/1884/origem/cap09.htm Consulta em 25/7/2020.

LOUREIRO, Isabel Maria. Rosa Luxemburg: breve perfil de uma revolucionária. In: Trans/Form/Ação vol.17 Marília Jan. 1994.

https://www.scielo.br/scielo.php? script $=$ sci arttext\&pid $=\mathrm{S} 0101-$

31731994000100007\&lng=en\&nrm=iso\&tlng=pt Consulta em 3/8/2020.

\footnotetext{
Nome

1 Professora do Programa de Pós-Graduação em Educação (PPGE) da Universidade Tuiuti do Paraná (UTP). Dra. em Filosofia e História da Educação - UNICAMP. Líder do Grupo de Pesquisa/CNPq Trabalho, Educação e Políticas Educacionais/Linha Formação de Professores. Plataforma Lattes: http://buscatextual.cnpq.br/buscatextual/busca.do Orcid: https://orcid.org/0000-0002-8511-2313 E-mail: maria.pereira@utp.br
} 